\title{
Effect of auto-transplantation of bone marrow on the nerve autography in the dogs
}

\author{
O.H. Al-Hyani \\ Coll. of Vet. Med./ Unive. of Mosul
}

\begin{abstract}
The research was conducted to study the repair of transected sciatic nerve through by grafting sciatic nerve with nerve segment and addition of bone marrow in dogs. Twelve adult dogs from both sexes was used. They was divided into two groups, six animals in each group. The left sciatic nerve was used as a model in this research for monitoring the process of nerve repair. In group one, the sciatic nerve was transected and a piece of nerve about $1 \mathrm{~cm}$ in length was removed, and the resultant gap was repaired by autotransplantation with a segment of nerve harvested from the median nerve of the forelimb with the consideration that the harvested median nerve segment was slightly longer than the resected sciatic nerve segment. The implanted nerve segment was sutured with sciatic nerve using non absorbable suture (nylon 510). In group two, the same surgical procedure was performed as in group one, but a bone marrow that aspirated from the same animal was applied on the nerve transplantation. The assessment of sciatic nerve repair was accomplished by studying the clinical observation of normal physiological function of the operated limb, additionally studying the histological changes on the nerve graft transplantation at 30 and 45 postoperative days. The study was revealed, the application of bone marrow on the nerve graft segment was enhanced the degree of healing of transected sciatic nerve that indicated by improvement the functional use of affect hind limb clinically, with improvement the vasculrization of nerve graft segment and increase proliferation of nerve cells (Schwann and microglial cells) with extension of collagen fibers that aid to bridge the sciatic nerve with grafted nerve segment histologicaly rather than in group one.In conclusion the addition of bone marrow on the nerve graft segment accelerate the degree of healing of transected sciatic nerve with improve the functional use of operated limb.
\end{abstract}

\section{Introduction}

Peripheral nerve injuries are common, and there is no easily available formula for successful treatment. Incomplete injuries are most frequent(2). Nerve injuries can be classified into three major groups:- neurapraxia, axonotmesis, and neurotmesis. Neurapraxia is characterized by local myelin damage, usually secondary to compression. Axon continuity is preserved, and the nerve does not undergo distal degeneration.Neural tissue is one of the important tissue of the body which recovers extremely sluggishly after being injured . Nerves are similar to electrical cable and contain many fibers (axons). Some of these fibers are sensory provided feeling in defined area, and some are motor activating muscles and sweat gland. Gap between nerve endings can occur as a result to injuries that have been not repaired or because sections of nerve have been removed(1).Axonotmesis is defined as a loss of continuity of axons, with variable preservation of the connective tissue elements of the nerve. Neurotmesis is the most severe injury, equivalent to physiologic disruption of the entire nerve; it may or may not include actual nerve transaction. Neurotmesis occurs when a nerve, along with its surrounding stroma, ecomes completely disconnected. There is no spontaneous recovery and even after surgery prognosis is poor. This type of injury is only seen in major trauma(3). Peripheral nerves injuries show both sensorial and motor functional changes(4). Experimental peripheral nervous injuries at the sciatic nerve may be provoked through a number of procedures, such as: smashing by compression, transsection, stretching and freezing. Several factors such as magnitude, duration and mechanism of compressive trauma are important to determine injury degree (5). 
New alternative techniques for surgical repair $(6,7)$ and the use of physical therapeutic resources (laser, electricity and ultra-sound) that might stimulate nerves morphological regeneration $(3,8)$. In extensive injuries, loss of tissue may result in a nerve gap.Numerous techniques have been used to obtain reapposition of severed nerve ends. These includes stretching of the nerve stumps by immobilizing the mesonerum and surrounding tissues, joint flexion to shorten nerve course, transposion of nerve route, osseous resection and limb shorting, nerve pedicle flaps, gap tabulation with aviary of materials, direct neurotization of muscle and nerve grafting $(9,10,11)$.Three major types of auto graft are cable, trunk, and vascularized nerve grafts. Cable grafts are multiple small-caliber nerve grafts aligned in parallel to span a gap between fascicular groups. Trunk grafts are mixed motorsensory whole-nerve grafts. Trunk grafts have been associated with poor functional results, in large part due to the thickness of the graft and consequent diminished ability to revascularize after implantation. The most common source of autograft is sural nerve, anterior branch of the medial antebrachial cutaneous nerve, median nerve, the lateral femoral cutaneous nerve

\section{Material and methods}

The proximal and distal region of median nerve segment was sutured with sciatic nerve using nylon $5 / 0$, then the site of incision was closed routinely. In the group two same surgical procedures in group one was used with the application of about $2 \mathrm{ml}$ of fresh bone marrow aspirated from femoral bone of the same animal on the nerve implant segment. All animals in both groups was administered with penicillin and streptomycin postoperatively for about 5 days. The dependable parameters used to evaluate the progress of sciatic nerve repair was through assessment the return of hind limb to normal function, and any possible gross changes could occurs in the muscles of the hind limb, and also by the histological examination of the implantation site after biopsy collection at 30 and 45 and superficial radial nerve(12,13). The technique of nerve grafting involves sharply transecting the injured nerve ends to excise the zone of injury. The nerve ends should display a good fascicular pattern. The defect is measured, and the appropriate length of graft is harvested to allow reconstruction without tension. If the injured nerve has a large diameter relative to the nerve graft, several cable grafts are placed in parallel to reconstruct the nerve(2). Bone marrow is one of the important tissues that responsible for blood cells formation, these tissue are called hemopiotic tissue. Two types of bone marrow are present: red(active) and yellow(in active) marrow. The red marrow was found at the end of long bones, ribs, sternum and ischium $(13,14)$. The mesenchymal cells that isolated from bone marrow have ability to differentiation into different cells such as fibroblast and chondrocyte also the stem cells can be to form some connective tissue (15). The study is designed to follow the repair of transected sciatic nerve through by fill the gap of it with nerve auto graft and study the effect of auto transplantation of bone marrow on the healing process of nerve graft transplantation.

postoperative days.The study was performed on the twelve adult dogs from both sexes. They divided into two groups, six animals for each group. All the animals are premedicated with atropine sulfate $(0.05 \mathrm{mg} / \mathrm{kg}$ i.m. $)$ and anesthetized after 15 min. from premedication with a mixture of xylazine and ketamine $(2 \mathrm{mg} / \mathrm{kg}$ and $10 \mathrm{mg} / \mathrm{kg}$, i.m. ,respectively). The left sciatic nerve was used in this study as example for peripheral nerves. In the group one after anesthesia, the left lateral femoral region surface was prepared for aseptic surgery, The left sciatic nerve was exposed by inducing about $10 \mathrm{~cm}$ skin incision and dissection to subcutaneous tissue and gluteal muscles without any damage to surgical site. The sciatic nerve was located and a piece of about $1 \mathrm{~cm}$ was resected from it. Then the gap that induced in the 
sciatic nerve was filled by implantation with a segment of median nerve harvested from the forelimb as autograft, which was slightly longer than the resected piece of

\section{Results}

\section{A- Clinical estimations:-}

In group one, the animals was suffered from paralysis of left hind limb after one week, but at the end of second week, some very little trials to put weight on the affected limb. The ability of animals to stand on the affected limb was increased at the end of $4^{\text {th }}$ postoperative week with few trials to move. At the sixth week, the animals have more controlled movement with the ability to use the affected limb for scratching their bodies. The gluteal muscles was showed little degree of atrophy. The response of animals to pin prick test on the affected limb was present and clear at the $5^{\text {th }}$ and sixth weeks after operation. In group two, like in group one the hind limb was paralyzed at the end of first week but little trials was showed to put weight on the limb. The chance for putting weight on the affected limb was increased in the second week with very little trials to use the limb during walking. The animals relatively in the four week was capable to stand on its limb but not completely with enhancement to use the limb during walking with increase animals depended to move the limb. The clinical signs for use of limb in six week are relatively similar to that seen in four weeks with improvement to the functional use of limb. No any signs of gluteal muscle atrophy was shown. The animals was respond to pin prick test at the affected limb between third and fourth week, and this response was increased in the sixth postoperative week.

\section{B-Histological changes:-}

In group one, the nerve graft segment that used to bridge between the two ending of transected sciatic nerve after 30 postoperative days was reveled presence new granulation tissue formation (collagen fiber, fibroblast and newly blood vessels) with infiltration of mononuclear inflammatory cells and hemorrhage (figure,1). Edema and severe secondary demyelination (wallerian degeneration) sciatic nerve. The forearm was not affected functionally after obtaining the median nerve graft, due to presence of more than one source of innervations to the limb.

also was showed (figure,2).Microglial nodules was showed in the gaps of the demyelinated area with proliferation of collagen fiber (figure,3). There was empty spaces surrounded with collagen fiber and newly blood vessels (figure,4). While the histological changes after 45 postoperative days, are represented by proliferation of collagen strand, Schwann cells and microglial cells with newly capillaries (figure,5). The area of collagen fiber proliferation was infiltrated by Schwann cells with proliferation of fibroblast as a longitudinal Colum (figure,6). Edema and demyelination was showed also.The empty spaces that surrounded with collagen fiber and newly blood vessels also was showed and still present. In group tow after 30 postoperative days, the histological changes was showed also new granulation tissue formation, mononuclear inflammatory cells infiltration with sever extension to collagen fibers as a bridge between the nerve and implant segment (figure,7). There was highly proliferation of Schwann cells rather than in group one with secondary demyelinzation (figure,8). There was proliferation of dense collagen fiber and newly capillaries formation (highly vascularization). Edema was showed (figure,9). Some sections was revealed more maturation for collagen strand (figure,10) with presence newly capillaries, macrophage and Schwann cells. The spaces was filled with granulation tissue with presence around it dense collagen strand and newly capillaries infiltrated by microglial cells and Schwann cells (figure,11).While after 45 postoperative days, the changes are represented relatively by bridging between the graft segment and nerve through by collagen strand (figure,12) infiltrated with microglial cells and Schwann cells and newly capillaries. The connective tissue was became more mature that consist of from dens collagen fiber (figure, 13). 


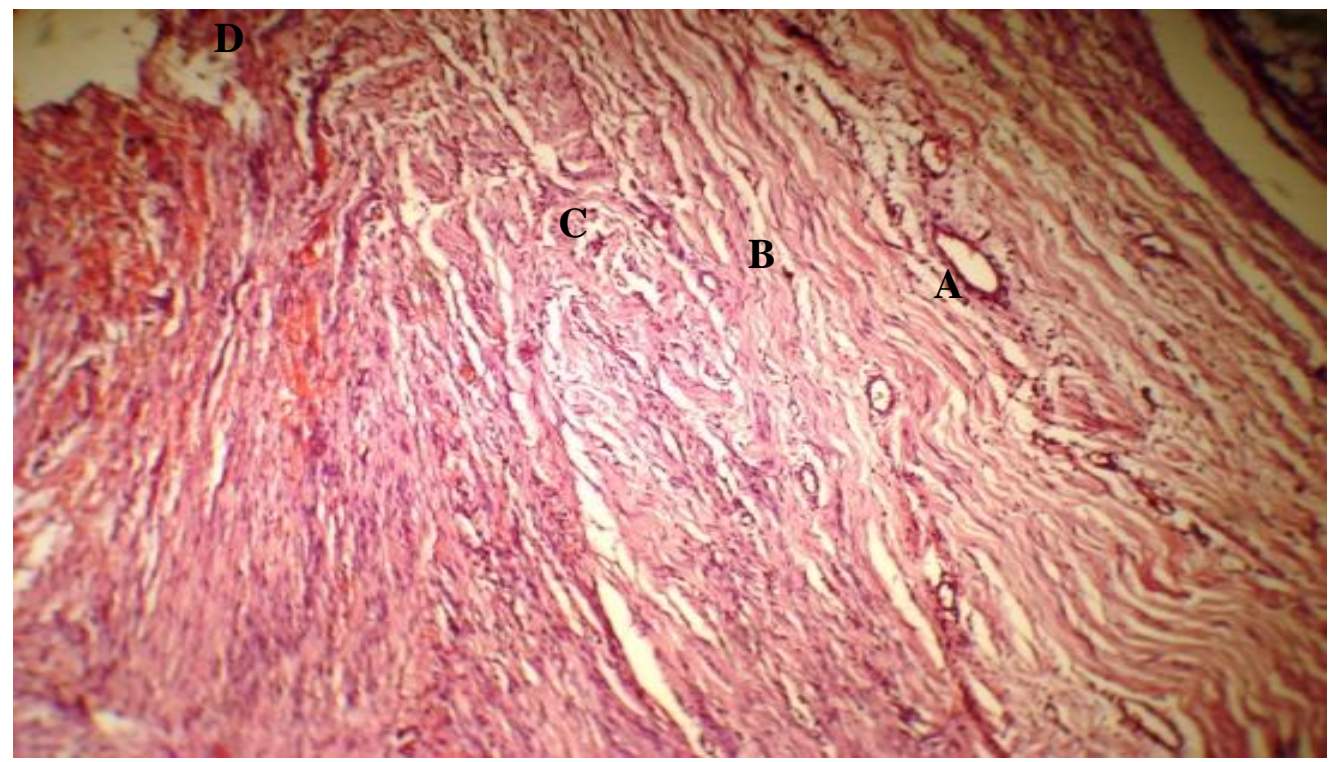

(Figure, 1) photomicrograph of nerve graft segment in group one in dog after 30 postoperative days show formation of collagen fiber (A), newly capillaries (B), infiltration of mononuclear inflammatory cells(C) with hemorrhage(D)(H\&E 90X)

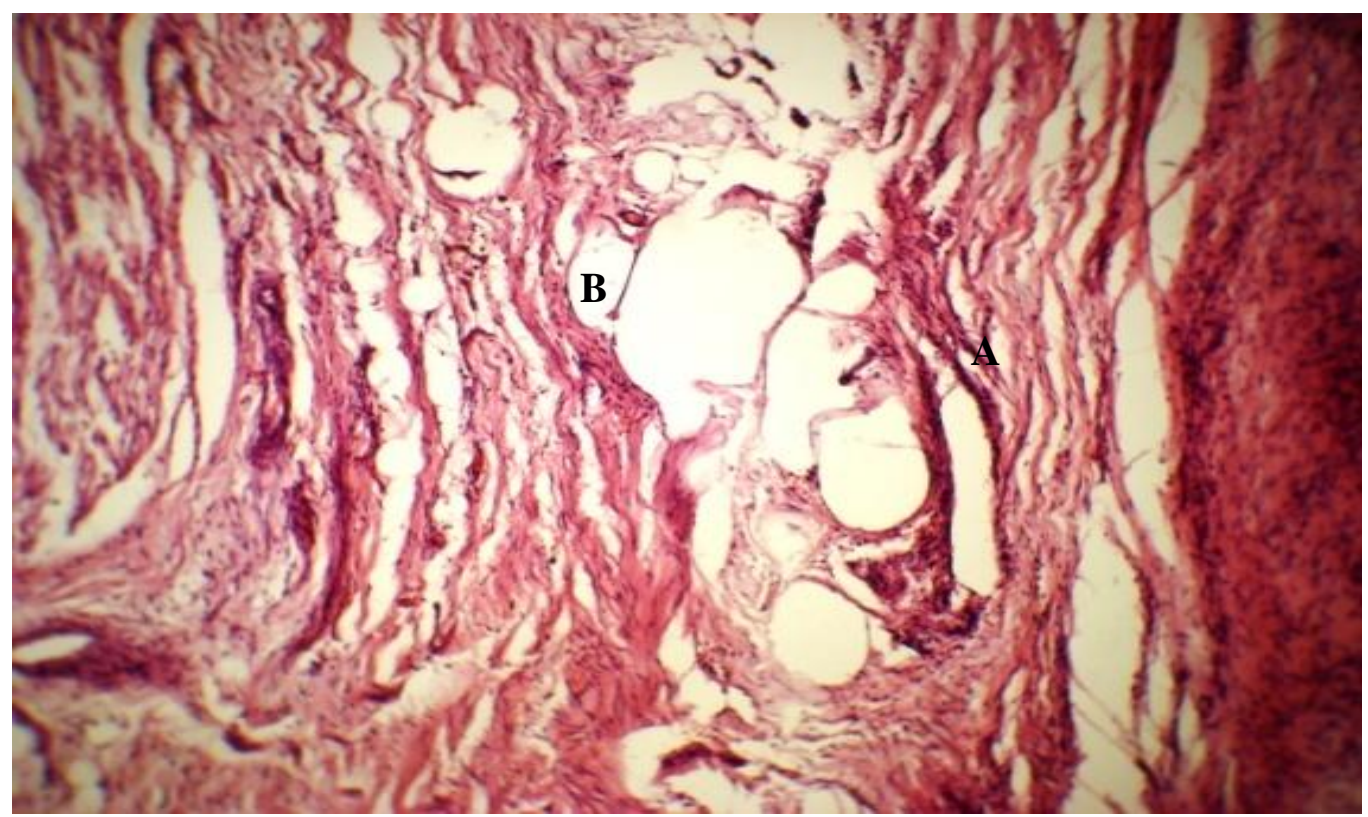

(Figure,2) photomicrograph of nerve graft segment in group one in dog after 30 postoperative days show edema (A)and secondary demyelination (B)

(H\&E 90X) 


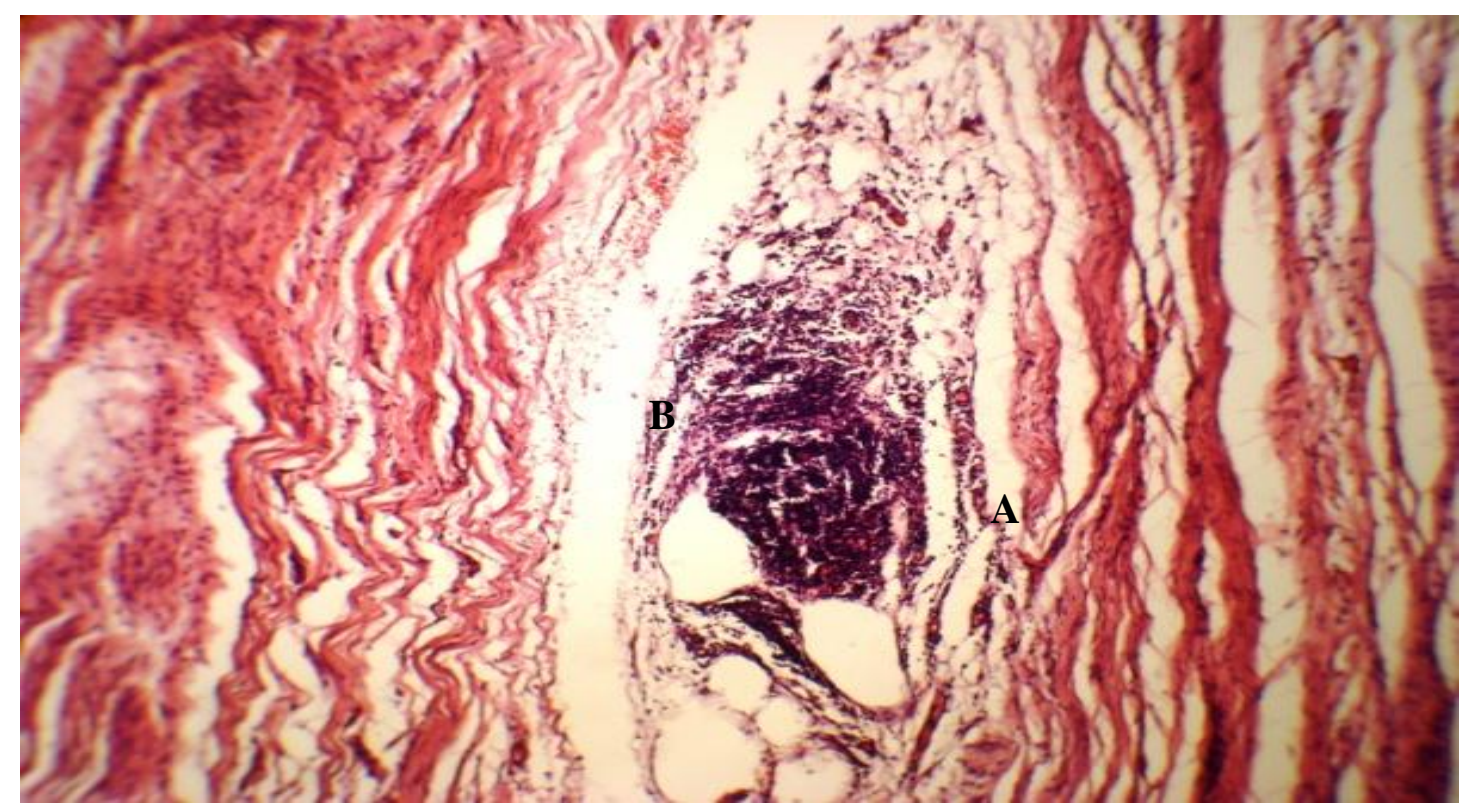

(Figure,3) photomicrograph of nerve graft segment in group one in dog after 30 postoperative days show nodules of microglial in the gaps of the demyelinated area(A) with proliferation of collagen fiber(B) (H\&E 90X)

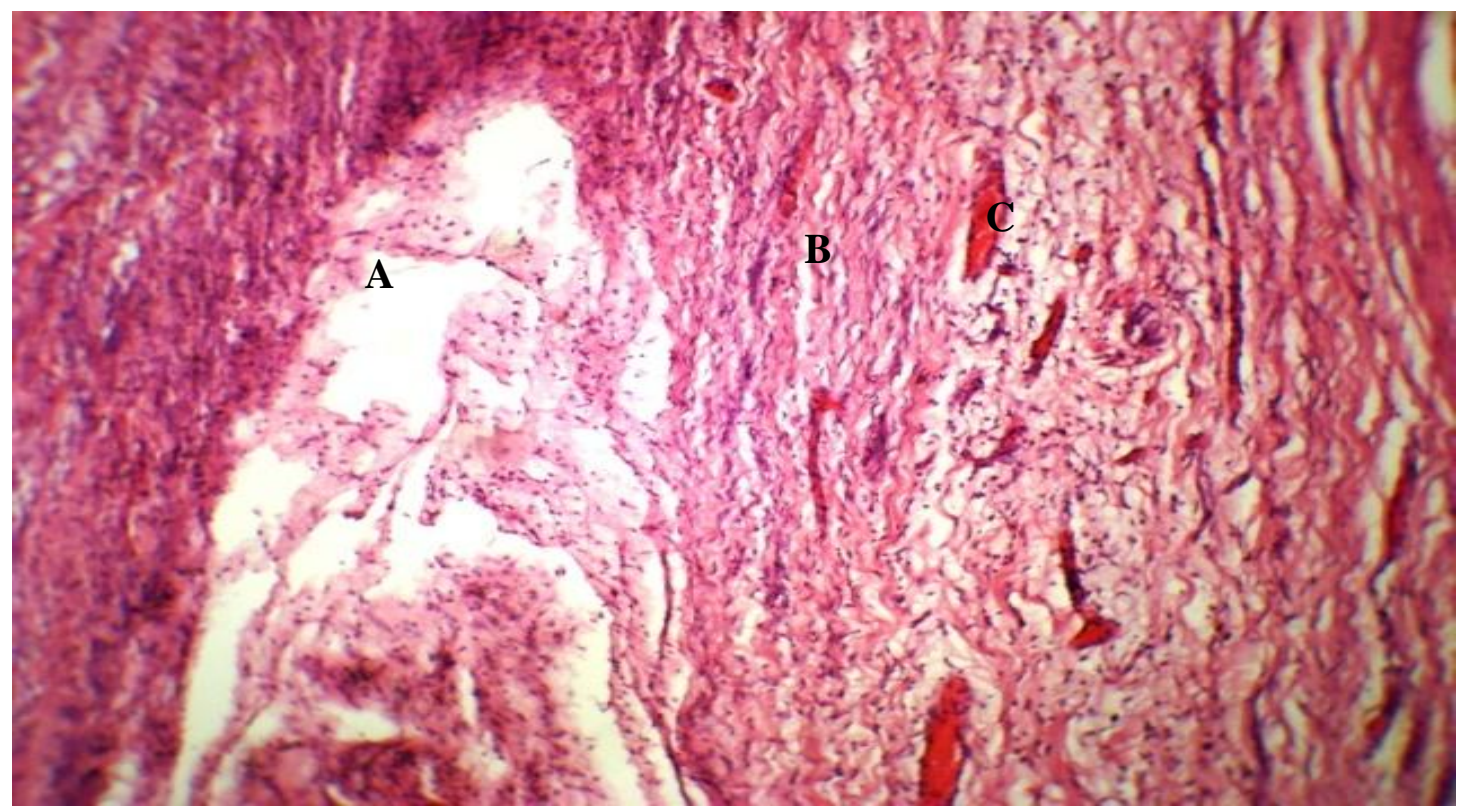

(Figure,4) photomicrograph of nerve graft segment in group one in dog after 30 postoperative days show empty spaces(A) surrounded with collagen fiber(B) and newly blood vessels(C) (H\&E 90X) 


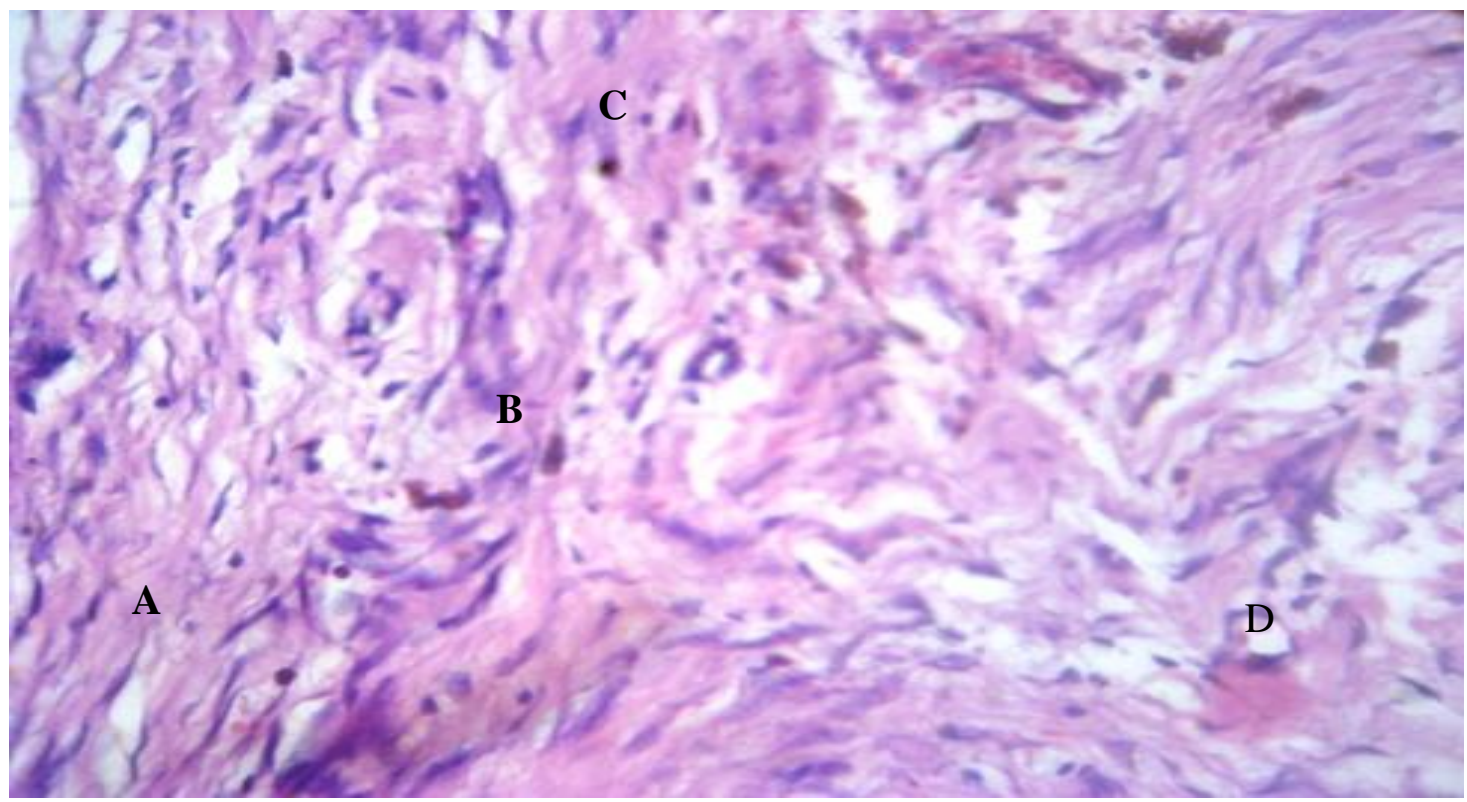

(Figure,5) photomicrograph of nerve graft segment in group one in dog after 45 postoperative days show proliferation of collagen strand(A)Schwann cells(B) and microglial cells(C) with newly capillaries(D) (H\&E 90X)

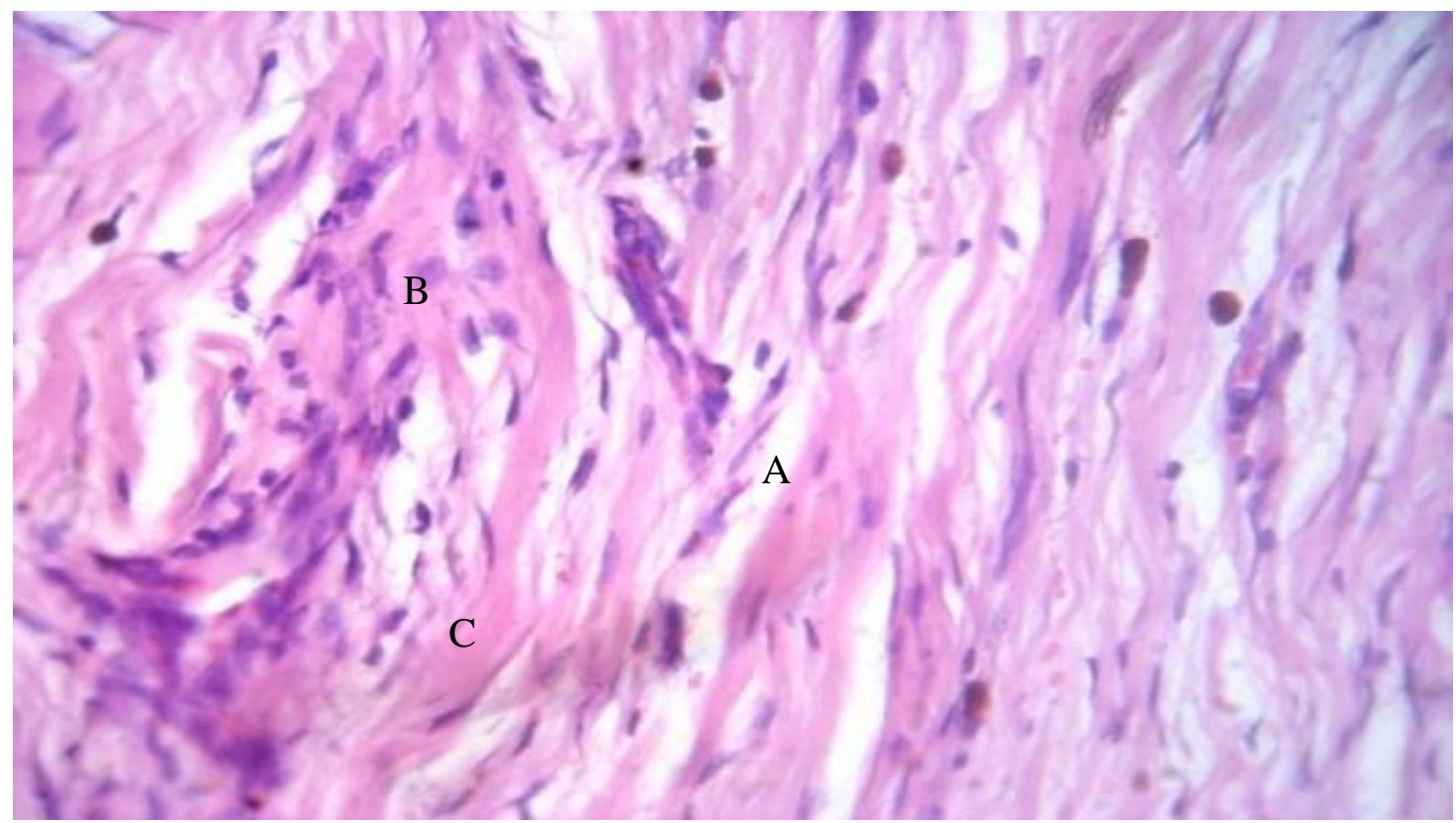

(Figure,6) photomicrograph of nerve graft segment in group one in dog after 45 postoperative days show collagen fiber proliferation(A) infiltrated by Schwann cells(B) with proliferation of fibroblast as a longitudinal Colum(C) (H\&E 90X) 


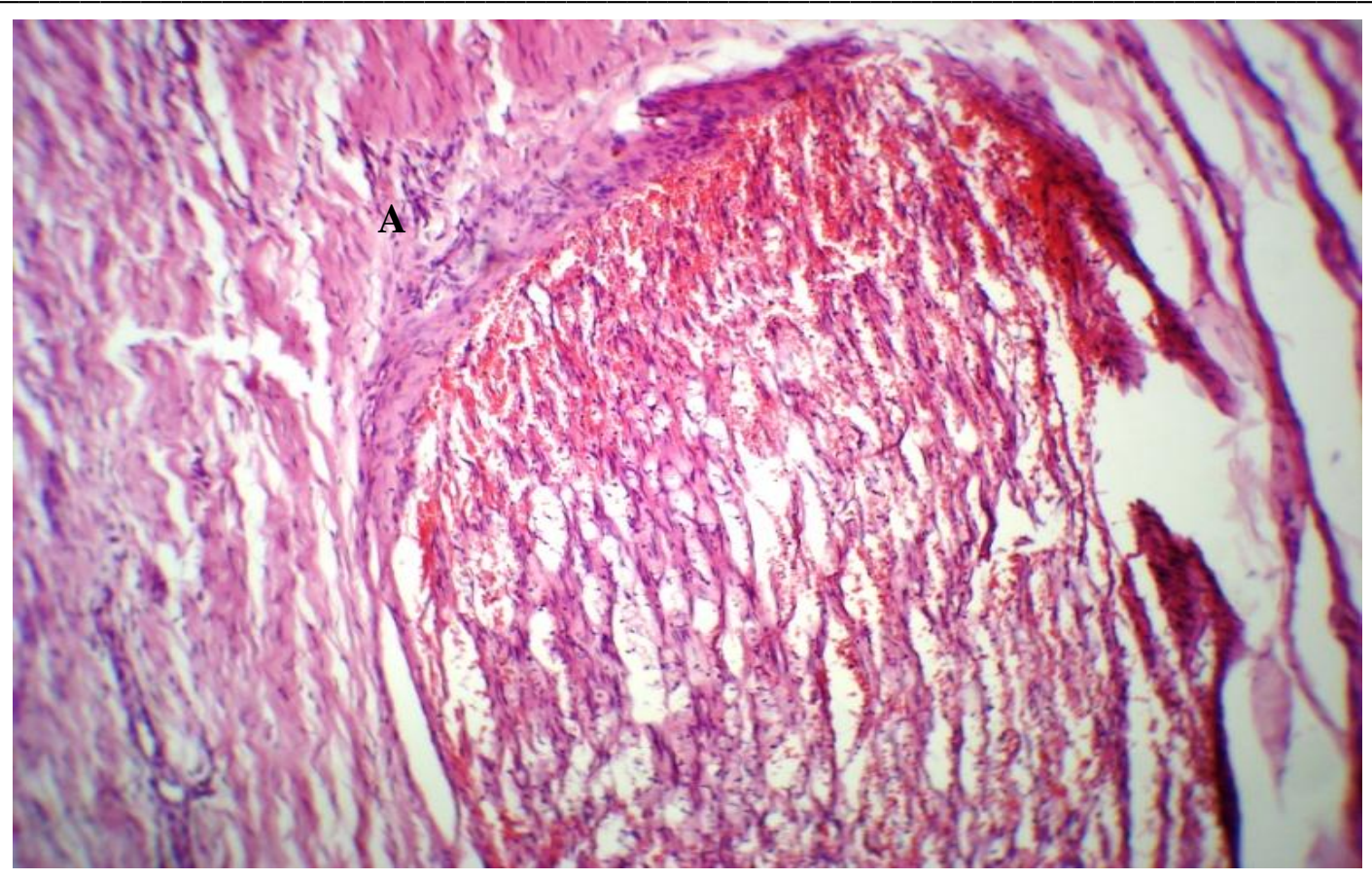

(Figure,7) photomicrograph of nerve graft segment in group tow in dog after 30 postoperative days show sever extension of collagen fibers (A) (H\&E 90X)

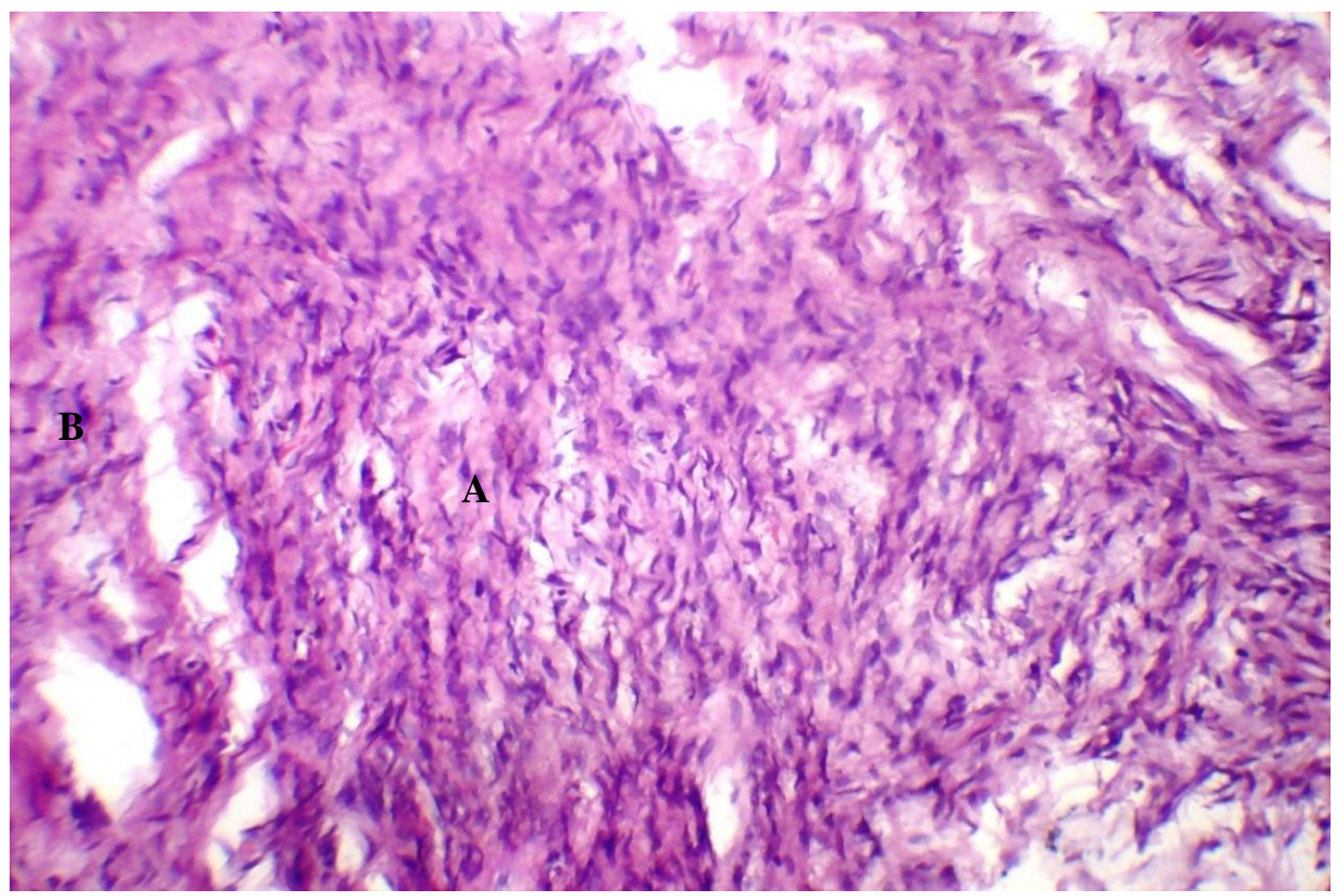

(Figure,8) photomicrograph of nerve graft segment in group tow in dog after 30 postoperative days show highly proliferation of Schwann cells(A) and secondary demyelinzation(B) (H\&E 90X) 


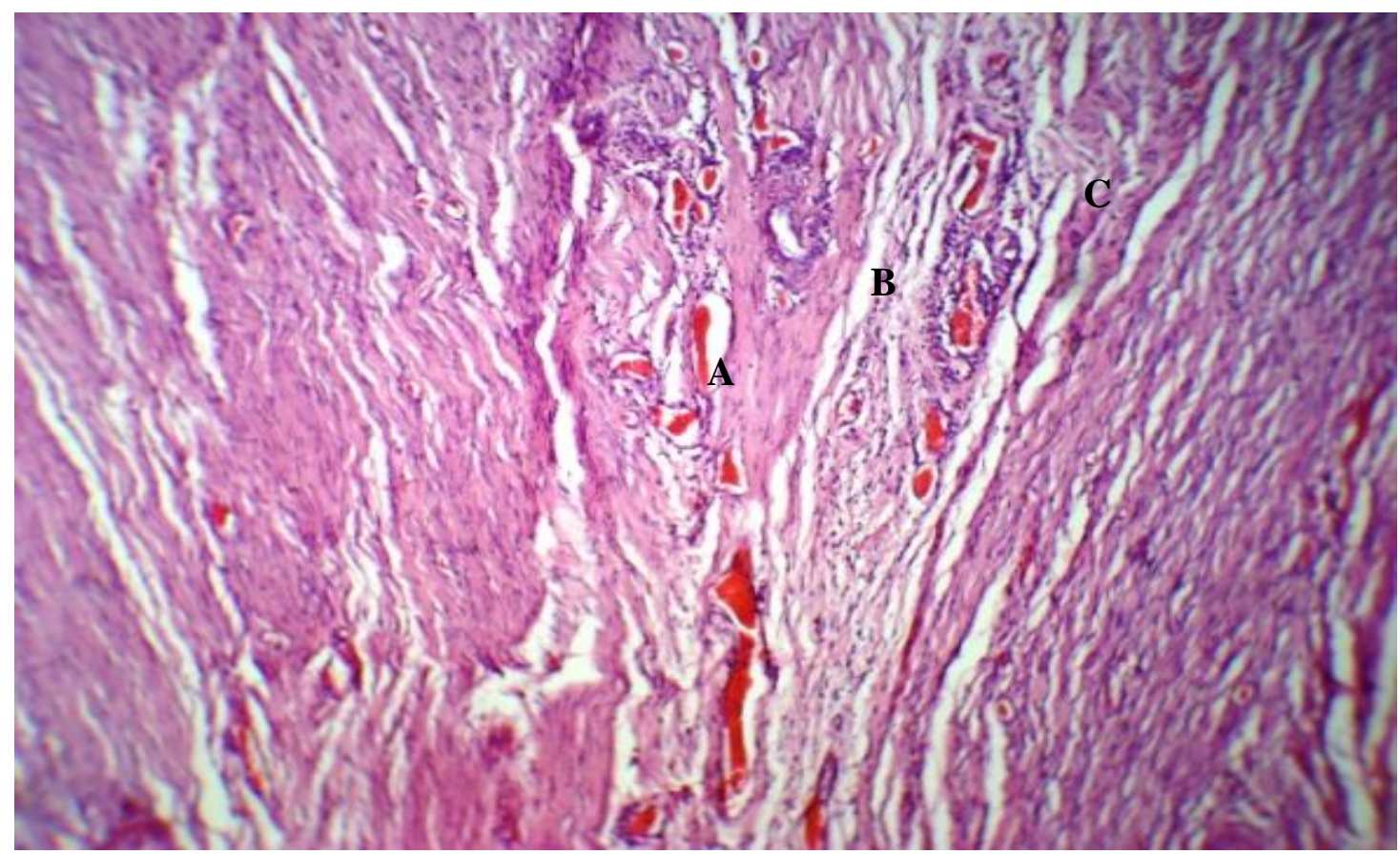

(Figure,9) photomicrograph of nerve graft segment in group tow in dog after 30 postoperative days show proliferation of dense collagen fiber(A), newly capillaries formation (highly vascularization)(B) and edema(C) (H\&E 200X)

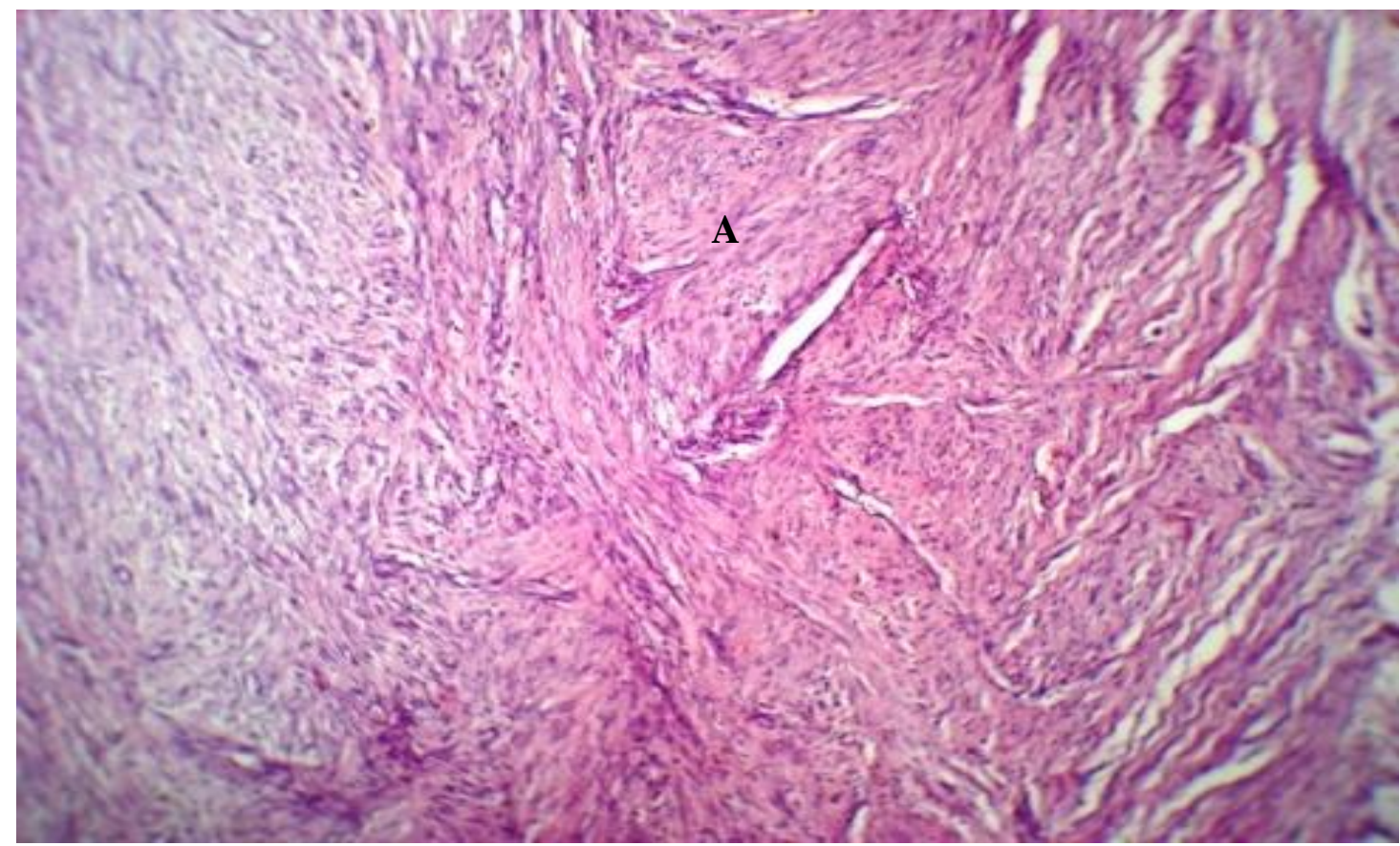

(Figure,10) photomicrograph of nerve graft segment in group tow in dog after 30 postoperative days show more maturation for collagen strand(A) (H\&E 90X) 


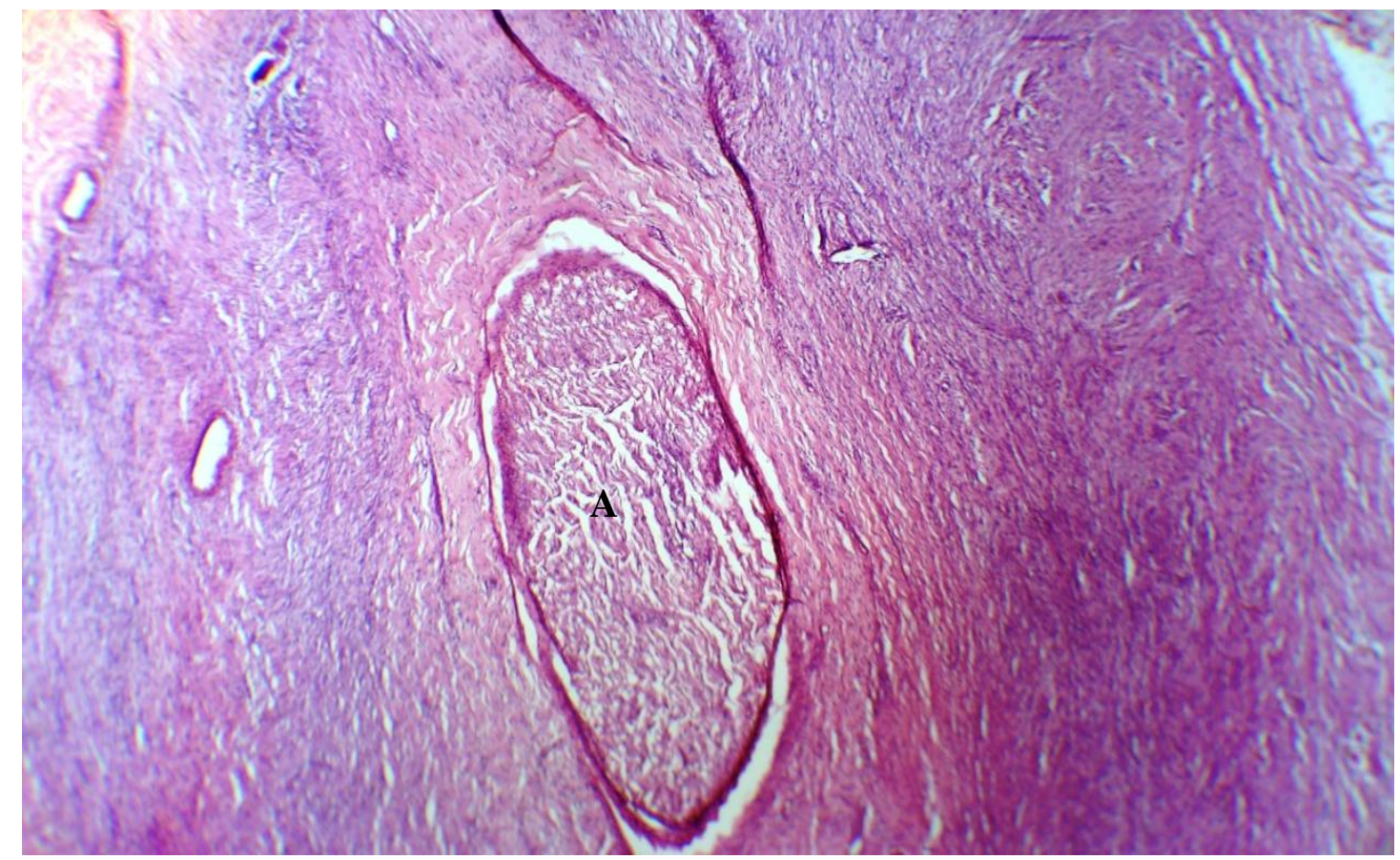

(Figure,11) photomicrograph of nerve graft segment in group tow in dog after 30 postoperative days show the spaces was filled with collagen fibers (A)

(H\&E 90X)

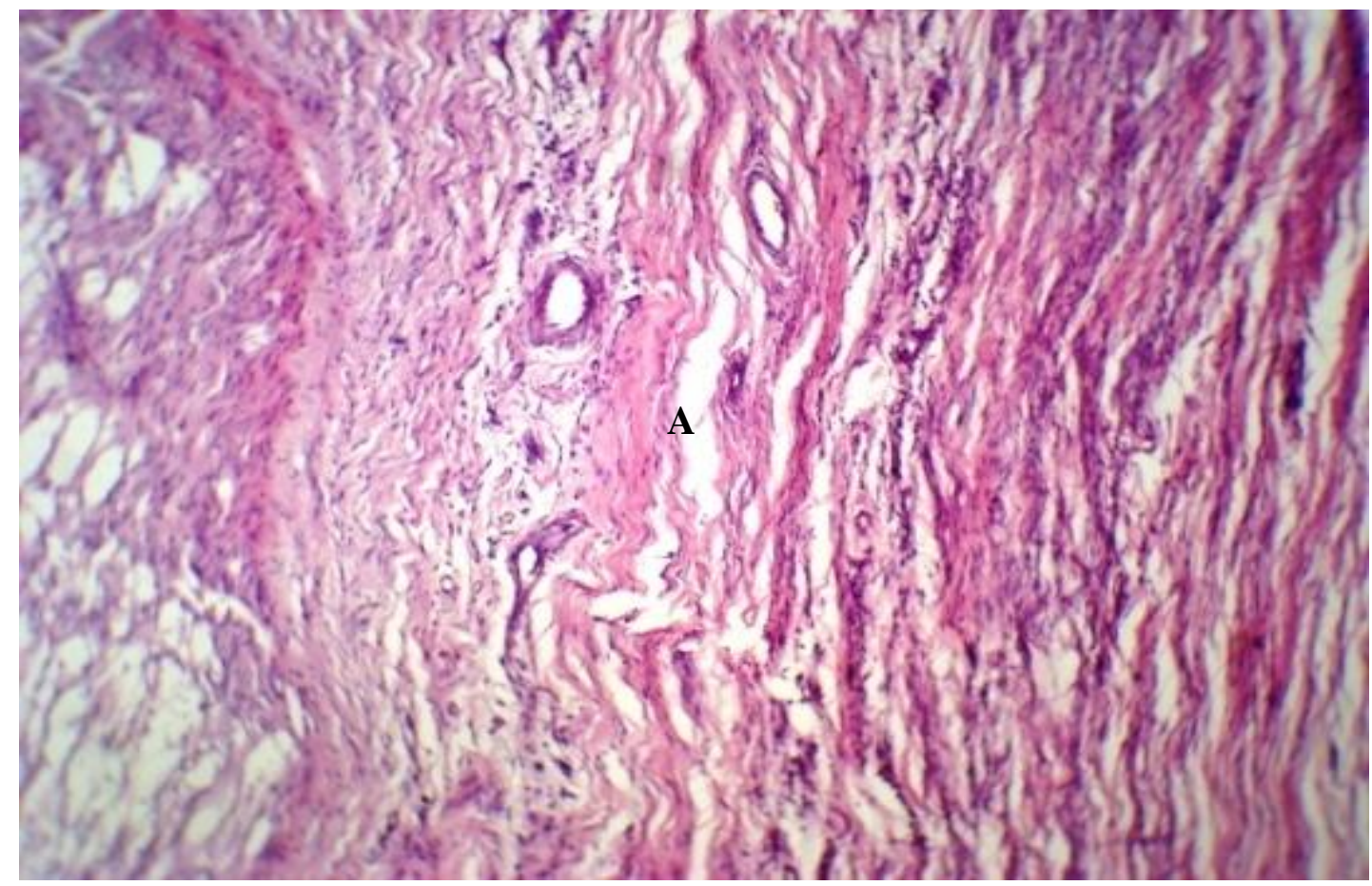

(Figure,12) photomicrograph of nerve graft segment in group tow in dog after 45 postoperative days show bridging between the graft segment and nerve through by collagen strand(A) (H\&E 90X) 


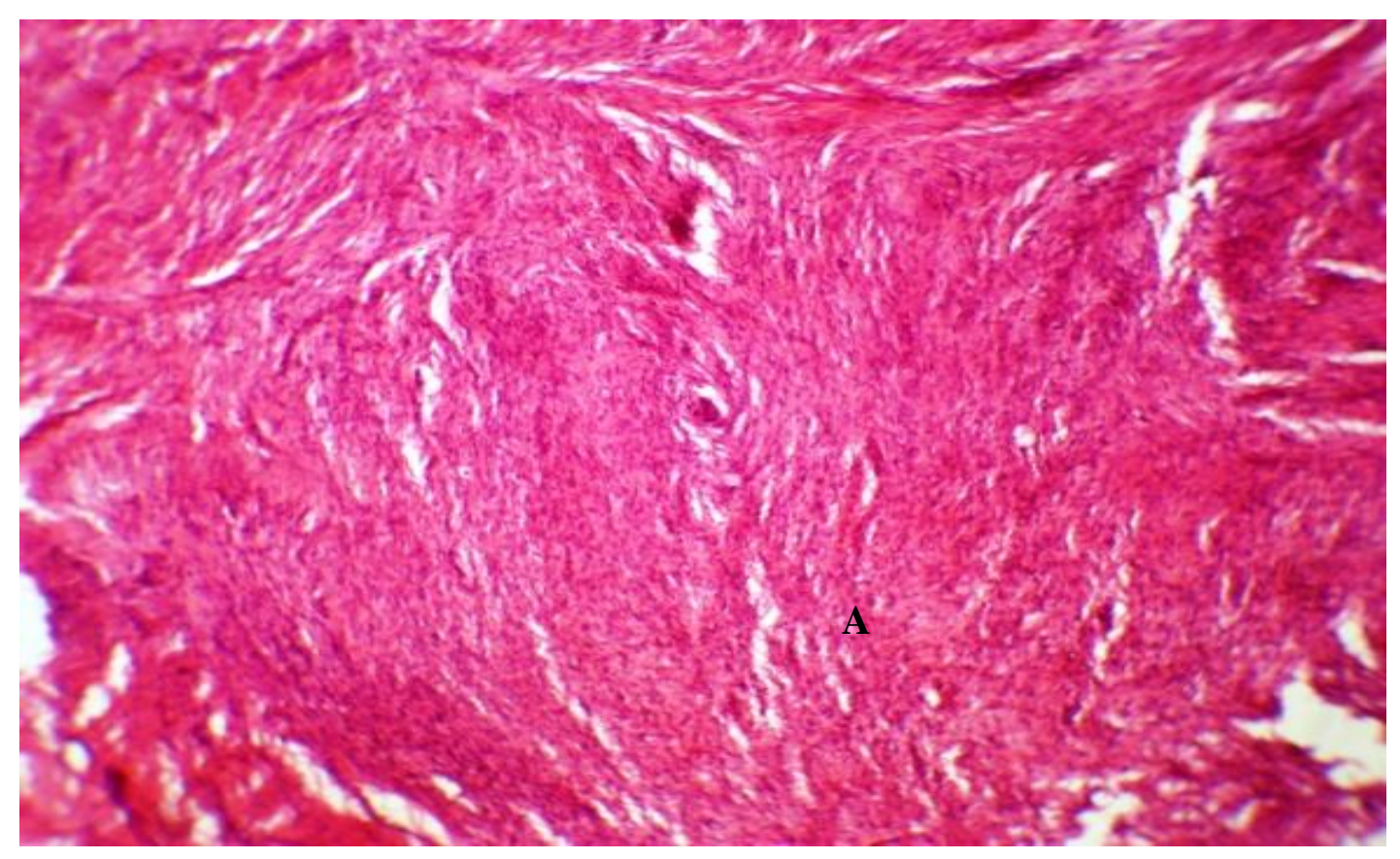

(Figure,13) photomicrograph of nerve graft segment in group tow in dog after 45 postoperative days show more maturation for connective tissue that consist of from dens collagen fiber(A) (H\&E 370X)

\section{Discussion}

When a nerve is a cut, it's a temp to regenerate. Fibrous sprout out of the nerve at the near end (proximal) and grow across the gap towards the far end (distal) at about $1 \mathrm{~mm} /$ day. Recovery is variable and always incomplete. The degree of recovery depends of many factors and is generally poor when surgical repair has not occurred. However, in group one the clinical use of affected hind limb was restricted only by appearance some trials to put the foot on the ground in the standing position with absence or very little attempts to use the limb during walking of the animal. Also in this group the return the sensation to the limb was retarded and weak with some degree of gluteal muscle atrophy, and this could be due to that nerve function may be initially worse after the any nerve graft operation, recovery is very slow taking months or years for function never return to normal state after the graft operation (1). The authors $(16,17)$ was mention the success of surgical nerve repair depended up on some factors such as the type of nerve involved can determine the course of healing where pure motor or sensory nerve usually has a more uncomplicated recovery while mixed nerves have the potential for transposition of axons during regeneration and there for the potential for improper end organ reinnervation, which can result in patient disorientation and a low level of ultimate functional recovery.The atrophied of muscles was due to never injury and disuse of limb and this feature was agreements with (12) where in major peripheral nerve injuries, After denervation, distal structures undergo many changes, such as soft tissues become fibrotic and stiff, muscle atrophies and undergoes interstitial fibrosis but remains viable for at least 2 years and early reinnervation produces superior functional return. Nerve grafts are similar to other devascularized tissue implants. Regeneration of blood supply must be provided by surrounding tissue to provide nutrition. In this research, the histopathological changes of auto nerve graft in group one was reveled presence 
newly granulation tissue and blood vessels formation with proliferation of nerve cells (Schwann cells, microglial cells) and the spaces that present between the graft segment and nerve or that result from suture materials was filled slightly with collagen fibers which act as abridge where after a transaction of a nerve, regeneration requires the survival neuron body cells. The growth of axons across the injury site and reconnection of these axons with their appropriate targets(18). These signs was indicated to live and viability of nerve tissue graft because any lack of vascularization lead to necrosis of graft due to destruction of Schwann tubules and failure of axonal regeneration through the graft. The danger is compounded in allograft and heterografts (19). In a mixed nerve there is no difference between growth and maturation of the sensory and motor fibers.Following axonal transection, a sequence of pathologic events occurs in the cell body and axon. The cell body swells and undergoes chromatolysis, a process in which the Nissl granules (i.e., the basophilic neurotransmitter synthetic machinery) disperse, and the cell body becomes relatively eosinophilic. The cell nucleus is displaced peripherally. This reflects a change in metabolic priority from production of neurotransmitters to production of structural materials needed for axon repair and growth, such as messenger RNA, lipids, actin, tubulin, and growth-associated proteins. Shortly after axonal transection, the proximal axon undergoes traumatic degeneration within the zone of injury. In most instances, the zone of injury extends proximally from the injury site to the next node of Ranvier, but death of the cell body itself may occur, depending on the mechanism and energy of injury. In the more severe cases of injury, an active $\mathrm{Ca}^{2}+$ mediated processknown as Wallerian degeneration, takes place distal to the lesion. Within hours of injury, myelin and axons break up to form ellipsoids. By 48 to 96 hours after injury, axonal continuity is lost and conduction of impulses no longer occurs. Degradation of the myelin and axons occurs due to a $\mathrm{Ca}^{2}+$ activated release of proteases by Schwann cells. The Schwann cells are of vital importance in Wallerian degeneration, as they rapidly divide into daughter cells that up-regulate gene expression for molecules to assist in both the degeneration and regeneration processes. The Schwann cells also work in conjunction with macrophages, supplying them with cell debris to engulf and remove. There is a codependence between these cells as the macrophages are mitogenic to Schwann cells and participate with Schwann cells in the provision of trophic (feeding) and tropic (guidance) factors for regenerating axons. Obviously, there are a number of mediators that play a role in Wallerian degeneration. These mediators include serotonin and histamine released by mast cells which enhance macrophage migration and are also therefore pivotal in the process. It is possible other mediators may be involved but have yet to be discovered. The end result of the dynamic Wallerian degeneration is a shrunken nerve skeleton with intact connective tissue and perineural sheaths and multiplying Schwann cells. In more severe injuries the process is complicated by vigorous inflammation and edema. Fibroblasts proliferate and a dense fibrous scar causes a fusiform swelling of the injured segment. (20,21,12) .Hemorrhage was developed as a result of bleeding associated with incision the nerve. The causes of infiltration of inflammatory cells may be due to presence of suture material or response to inflammatory reaction occurrence.Edema may be due to tissue excision where in more severe nerve injuries the process is complicated by vigorous inflammation and edema(20,21).In a serious trauma like crush, a short period of localized total or subtotal ischemia is followed by evident increase in the endoneural fluid pressure and impairment of the normal capillary blood flow in the endoneurium. All of these results in the release of the endogenous chemical mediators, increase in the vascular permeability and impairment of the blood-nerve barrier. Endoneural and intraneural edema with 
$\begin{array}{llll}\text { AL-Qadisiya Journal of Vet.Med.Sci. } & \text { Vol./11 } & \text { No./2 }\end{array}$

inflammatory response follows this process (22,23).Demylination was occurred secondary follow degeneration of the axon and this process was described with the axon as wallerian degeneration. Demylination was tend to be secondary to or concomitant with neuroaxonal injery(24). In group two, the addition of bone marrow to nerve graft was improvement the clinical use of affected limb rather than in group one where the animals was capable relatively (not completely) to put the foot on The ground during standing and walking position, and this is may be due to enhancement the healing of implant segment with nerve through newly granulation tissue and blood vessels formation with highly proliferation of nerve cells such as schawnn cells with increased proliferation of collagen fibers where the addition the bone marrow was improved the bridging between graft and nerve and this is feature was agreements with $(15,25,26,27)$ where was noticed the mesenchymal cells of bone marrow have ability to differentiation into different cells such as fibroblast, neurons and some connective tissues and improvement tissue healing. This capacity

\section{References}

1. Belcher H.J.C.R. Nerve surgery.(2010). (www.harry- belcher.couk/ home.htm)

2. Steve K, Lee MD, Scott W, Wolfe MD. (2000). Peripheral Nerve Injury and Repair. J. Am. Acad. Orthop. Surg.8:243-252

3. Seddon HJ.(1972). Surgical Disorders of the Peripheral Nerves. Baltimore,Williams \& Wilkins. 68-88.

4. Sunderl S. (1990). The anatomy and physiology of nerve injury. Muscle \& Nerve.13:771-84.

5. Diao E, Andrews A, Diao J. (2004). Animal models of peripheral nerve injury.Techn. Orthop. 14:153-62

6. DeS JM, Mazzer $\mathrm{N}$, Barbieri $\mathrm{CH}$, Barreira A.( 2003). The end-toside peripheral nerve repair functional and morphometric makes them a likely cellular source for clinical application in tissue repair therapies,. where the $(28,29)$ was founded the use of marrow stem cells in cases of peripheral nerves injuries is regarded as one of the most promising alternatives methods for treating nervous injuries and the bone marrow stem cells have an important regenerative potential after being transplanted in transectioned sciatic nerves' ends. Also the presence of Mononuclear cells stimulated nerve regeneration, most probably by speeding up the Wallerian degeneration process as well as stimulating the synthesis of neurotrophic factors (30). The authors (31) was founded the bone marrow stem cells combined to tubing technique promotes a better recovery of motor function and a more abundant regeneration in an acute nerve defect model. Exact mechanism accounting for this response is not fully understood. Additional research is necessary for understanding the mechanisms of differentiation occurred within the tube filled with the preparation of adult bone marrow stem cells, able to promote nervous regeneration induction. study using the peroneal nerve of rats. J.Neurosci Methods. 136:4553.

7. Oliveira EF, Mazzer N, Barbieri $\mathrm{CH}$, Deelbel EA.( 2004). The use of muscle graft to repair a segmentary nerve defect. An experimental study using the sciatic nerve of the rats as model. J Neurosci Methods.; 133:19-26.

8. Monte Raso VV, Mazzer N, Barbieri CH, Fazan VS. (2005). Can therapeutic ultrasound influence the regeneration of peripheral nerves?. J. Neurosci Methods. 42:185-92.

9. Berger FH, and Millesi h.(1978). Nerve grafting .clin.orthrop.and related res.133:49

10. Kline DG ,Hackeet ER, Davis GD, Myers B.(1972).Effect of mobilization on the blood supply 
and regeneration of injerd nerve .J.Surg.Res. 12:254.

11. Miyamoto y.( 1979). Experimental study on repair for peripheral nerves. Hiroshima. J.med.sci. 28:87.

12. Sunderland S.(1991). Nerve Injuries and Their Repair: A Critical Appraisal. New York: Churchill Livingstone. 243-252.

13. Cotter SM and Blue J. Bone marrow .In : Slatter DH . (1985). Text book of small animal sugy . W.B. Saunders Company Philadelphia. 1999-1203.

14. Rrywlin AM. Hemopoitic system .in: Kissan JM and Anderson WAD . (1985).Anderson Pathology $8^{\text {th }}$ ed. C.V. Mosby Company . 13251326.

15. Kadiyala S,Young RG, Thiede MA ,Bruder P.(1997). Cultured examineded canine mesenchymal stem cells transplant . 6(2):125-34.

16. Labelle JJ and Allen DE.( 1972). The peripheral nerve repair a review. J. Maine Med. Assoc. 63:164.

17. Brown PW.( 1972).Factors influencing the success of the surgical repair of peripheral nerves Surg. Clin. North. Am. 52:1137.

18. Madison RD, Arjchibald SJ. (1992). Wound healing, biochemical and clinical aspect" peripheral nerve injery".28:450- 87.

19. Starkweather RJ, Neviaser RJ, Adams JP,Parsons DB. (1978). The effect of devascularization on the regeneration of lacerated peripheral nerves:an experimental study .J.hand surg. 3:163.

20. Adam O.(2007).Peripheral Nerve Injury and Repair. Reviews: Surgery .TSMJ.8:29-33

21. Moldovan M, Sorensen J, Krarup C.(2006). Comparison of the fastest regenerating motor and sensory myelinated axons in the same peripheral nerve. Brain. 129(9):2471-2483.
22. Podhajsky RJ, Myers RR.(1999). The vascular response to nerve crush: relationship to Wallerian degeneration and regeneration. Brain Res. 1993; 623 :117-123

23. Ambrosio G, Tritto I.(1973). Reperfusion injury: experimental evidence and clinical implications. Am. Heart J. 138: 69-75.

24. Jubb KVF and Kennedy PC. (1970).Pathology of domestic animals .Academic Press, Newyork, London. 363-364.

25. Sharma s, Charg NK , Neliath AT, Subramanian c , Srivaastava K. (1992).Percutanous bone marrow grafting of osteotomies and bony defect in rabbits .Acta orthrop. Scand. 63(2):1166-9.

26. Insúa $A H$, Montaner $A D$, Rodriguez JM, Elías F, Fló J, López RA, Zorzopulos J.(2007). Py NTTTTGT Oligonucleotides as Tools in Tissue Repair Procedures. Topics in Tissue Engineering . 1-13.

27. Schwartz RE, Reyes M, Koodie L . (2002). Multipotent adult progenitor cells from bone marrow differentiate into functional hepatocyte-like cells. J Clin Invest 109:1291-1302

28. Choi BH, Zhu SJ, Kim BY, Huh JY, Lee SH, Jung JH.(2005). Transplantation of cultured bone marrow stromal cells to improve peripheral nerve regeneration. Int J Oral Maxillofac Surg. 34:53742.

29. Pereira Lopes FR, Camargo de Moura Campos L, Dias Correa J Jr, Balduino A, Lora S, Langone F, et al. (2006).Bone marrow stromal cells and resorbable collagen guidance tubes enhance sciatic nerve regeneration in mice. Exp Neurol. 198:457-68.

30. Lopes-Filho JD, Caldas HC, Santos FC, Mazzer N, Simes GF, Kawasaki- Oyama RS, AbbudFilho M, Oliveira AR, Toboga 
SR, Chueire AG.(2010).

Microscopic evidences that bone marrow mononuclear cell treatment improves sciatic nerve regeneration after neurorrhaphy. Microsc. Res. Tech. [PubMed ].

31. Jefferson BS, Daniel G, Javier A. R, Caroline M, Eduardo de A A, Denise CM, Christian V, Gustavo
L B, Cristiane V W B, Vinícius D S, Jaderson C. (2006).Bone marrow stem cells and plateletrich plasma effects on nervous regeneration and functional recovery in an acute defect model of rats' peripheral nerve. Acta ortop.bras. 14 (5): 1413-7852 .

\section{تأثير الزرع الأتي لنخاع العظم على الترقيع الذاتي للعصب في الكلاب}

$$
\text { كلية الطب البيطري/ أسامة الحياني الموصل }
$$

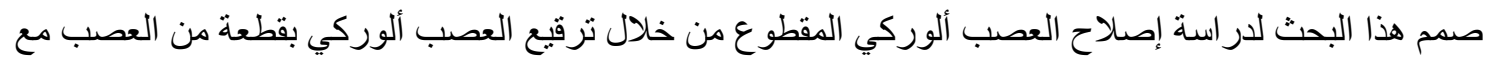

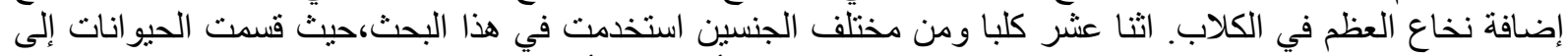

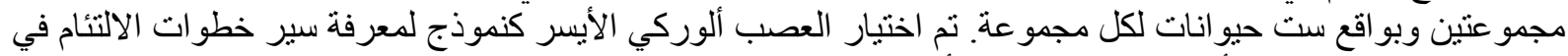

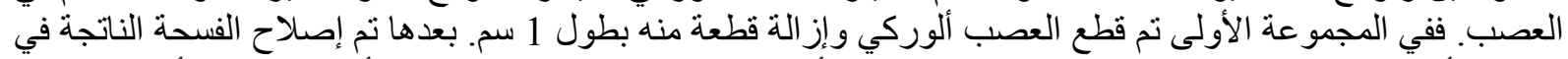

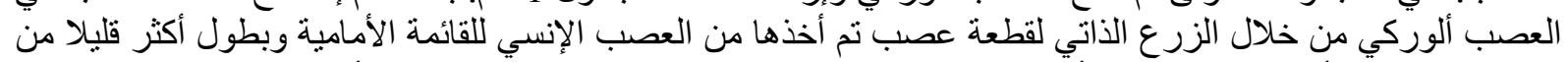

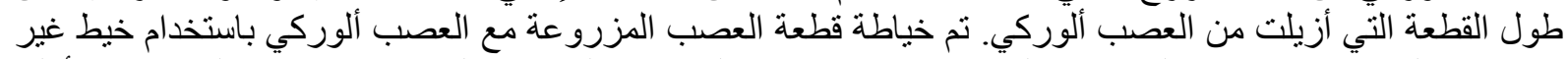

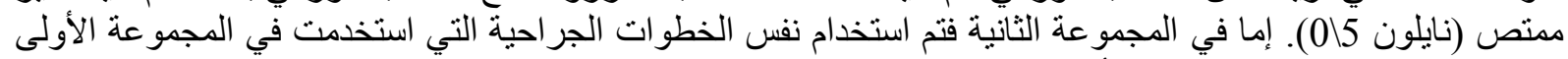

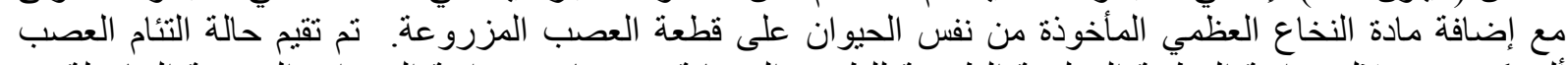

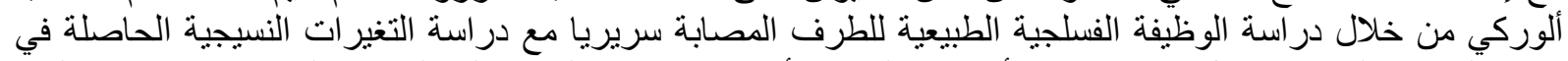

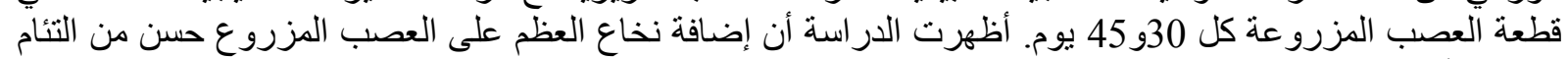

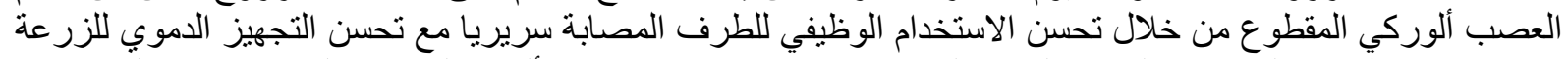

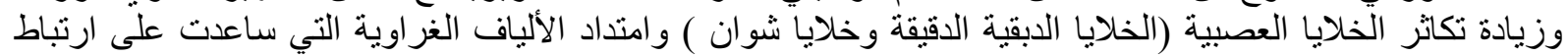

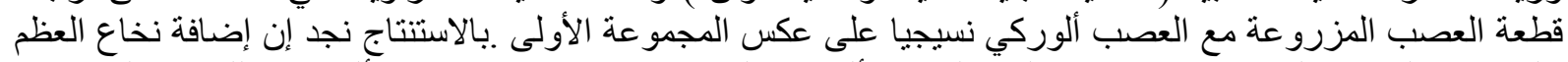

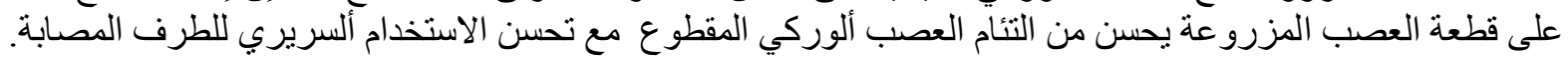

